\title{
Carbon Emissions Pinch Analysis (CEPA) For Emissions Reduction in the New Zealand Electricity
}

\section{Sector}

Martin J. Atkins ${ }^{1}$, Andrew S. Morrison, Michael R.W. Walmsley

Energy Research Group, School of Science \& Engineering, University of Waikato,

Private Bag 3105, Hamilton 3240, New Zealand;

Keywords: Carbon Emissions Reduction; Energy Planning; Pinch Analysis; Power Sector Planning;

\begin{abstract}
Carbon Emissions Pinch Analysis (CEPA) is a recent extension of traditional thermal and mass pinch analysis to the area of emissions targeting and planning on a macro-scale (i.e. economy wide). This paper presents an extension to the current methodology that accounts for increased demand and a carbon pinch analysis of the New Zealand electricity industry while illustrating some of the issues with realising meaningful emissions reductions. The current large proportion of renewable generation (67\% in 2007) complicates extensive reduction of carbon emissions from electricity generation. The largest growth in renewable generation is expected to come from geothermal generation followed by wind and hydro. A four fold increase in geothermal generation capacity is needed in addition to large amounts of new wind generation to reduce emissions to around 1990 levels and also meet projected demand. The expected expansion of geothermal generation in New Zealand raises issues of GHG emissions from the geothermal fields. The emissions factors between fields can vary by almost two orders of magnitude making predictions of total emissions highly site specific.
\end{abstract}

\section{Introduction}

As a major objective of the 2007 National Energy Strategy [1] the New Zealand Government set a 90\% renewable energy target for the electricity sector to meet by 2025 . To help achieve this new base load, the Government legislated against any new fossil-fuel based thermal generation for a 10 year interval from 2008 by making an amendment to the Electricity Act 1992. New Zealand already has a high

\footnotetext{
${ }^{1}$ Corresponding author, FAX:+6478560115, email address: matkins@waikato.ac.nz
} 
proportion of renewable generation $(67 \%$ in 2007$)$ mainly due to the large amount of hydro generation (55\%). However, there is a lack of hydro storage capacity, which leads to security of supply concerns in dry years [2]. In 1992 and 2008 there was a severe nation wide drought with very low hydro lake levels. The renewables target therefore became a topical issue, especially during the 2008 national election. Despite a change of government and repeal of the moratorium on new fossil fuel electricity generation, the $90 \%$ renewables target is seen as a key strategy to reduce greenhouse gas (GHG) emissions.

Although a high renewables target is an aspiration, detailed analysis of the actual effect on the generation mix, emissions levels, economic costs to the country, and security of supply impacts have not yet been thoroughly presented or debated in the public arena. Considering that almost all of the "easy" hydro generation capacity has already been fully utilised, a thorough analysis as to possible generation scenarios is needed, and it seems likely that geothermal generation will provide most of the extra "renewable" generation needed to reach the target and to meet increased electricity demand. However, despite the view that geothermal generation is renewable, it can have a significant "carbon footprint" depending on the geology and associated geothermal systems of the area, which needs to be accounted for in any analysis. This paper will use a novel method known as Carbon Emissions Pinch Analysis to examine the implications of the renewables target on the generation mix and emissions levels in 2025 .

\section{Carbon Emissions Pinch Analysis}

Carbon Emissions Pinch Analysis (CEPA) was first developed by Tan \& Foo and co-workers [3-5] and was based on the application of traditional pinch analysis techniques commonly utilised as a process integration tool by chemical and process engineers. Pinch analysis was developed in the 1970's and has been successfully applied to a number of areas including heat and mass integration to minimise energy and water usage. A detailed explanation of the pinch analysis methodology for heat integration can be found in Kemp [6] and Smith [7] and for mass integration in El-Halwagi [8] and Mann \& Liu [9]. Emissions targeting was originally confined to total site analysis, which focused on optimisation and emissions reduction of industrial sites [10]. CEPA extends the pinch analysis technique from industrial sites to broader macro-scale applications and can be readily applied to the electricity generation sector, although it can also be applied to primary energy usage. The only published case studies have been focused on the Irish electricity sector [11-13]. Sectoral and regional studies can also be conducted for 
emissions planning and reduction. CEPA can also be used to optimise the generation mix based on demand/emissions targeting (as above) including economic constraints, such as the cost of generation, carbon prices, and the like. Such analysis is beyond the scope of this paper, however it is anticipated that further analysis, including economic analysis will be conducted in the future. The method has also been extended to include Carbon Capture and Storage (CCS) and the additional required generation that needs to be provided due to the substantial energy penalties incurred by the use of CCS [14]. A review of the methodological developments to date has recently been presented [15].

A brief explanation of the technique is presented here; however for a detailed explanation of the methodology for constructing composite curves see Tan \& Foo [3] and Foo et al., [5]. The basis of the technique is constructing what are called composite curves of both the demand and supply. These composite curves are then manipulated and modified depending on the desired objectives. Example demand and supply composite curves are illustrated on the left in Fig. 1 for the data given in Table 1. The supply composite curve is constructed (shown as the solid black line in Fig. 1) by plotting cumulatively the quantity of electricity generated for the several fuel sources against total emissions from those sources. The fuel source with the lowest Emissions Factor (EF) (the amount of emissions produced per unit of electricity e.g. $\mathrm{ktCO}_{2}$-e/GWh) is plotted first, followed by the next highest and so on. The slope of the line is equal to the emissions factor. All emissions factors are expressed as carbon dioxide equivalent and include all relevant greenhouse gases.
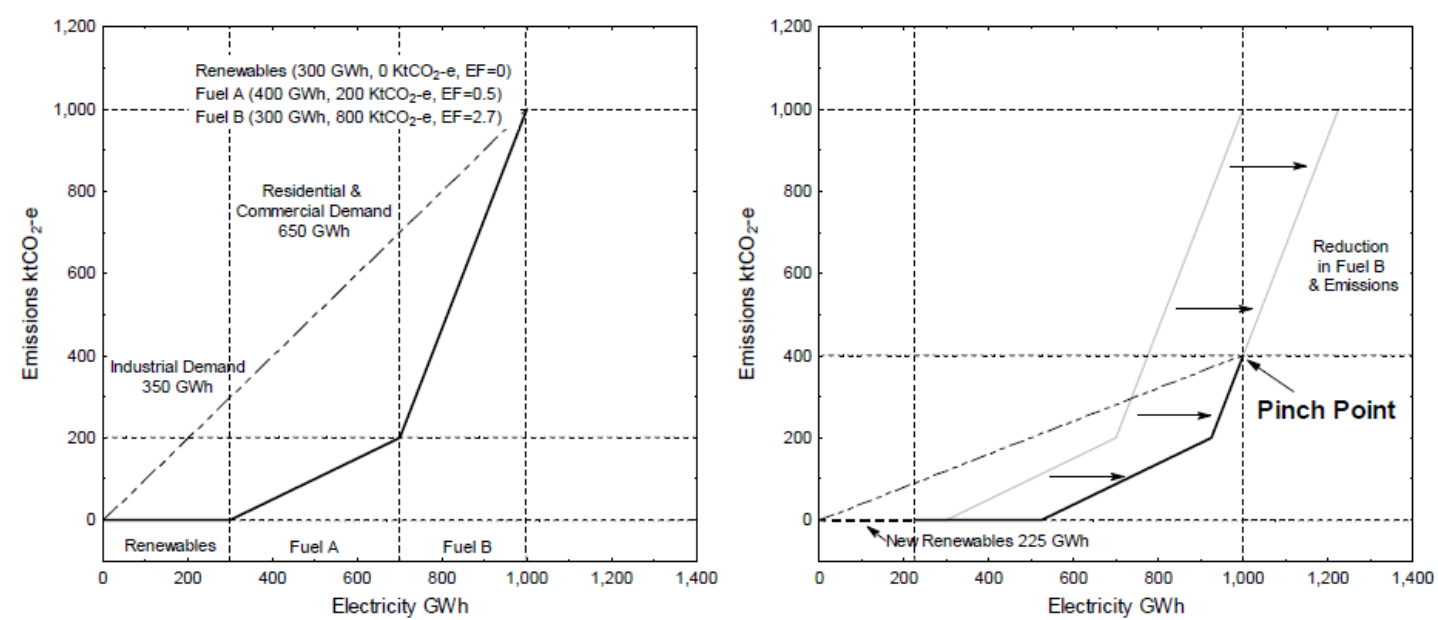

Fig. 1: Example demand and supply composite curves. 
Table 1 Example electricity and emissions scenario.

\begin{tabular}{cccc}
\hline & Wind & Hydro & Geothermal \\
\hline Additional Generation (GWh) & 6648 & 4762 & 10238 \\
Additional Installed Capacity (MW) & 2530 & 1090 & 1460 \\
Load Factor & $30 \%$ & $50 \%$ & $80 \%$ \\
\hline
\end{tabular}

The demand composite curve (dashed black line) is also constructed using the same method as the supply composite curve however as a first approximation it can be assumed that the emissions from the various demand sectors is proportionate to the electricity usage and therefore will produce a straight line from the origin to the end of the supply composite curve. The demand curve could consider demand by sector, as in this case, or also by region. The ends of the total supply and demand composite curves should coincide. The slope of the demand line then is known as the Grid Emissions Factor (GEF), which is simply the average total emissions factor or specific emissions for the entire system. In this example the GEF is equal to $1 \mathrm{ktCO}_{2}-\mathrm{e} / \mathrm{GWh}$.

Once the composite curves are constructed for the base case, a new demand curve is drawn that ends at the target demand and emissions levels. The graph on the right in Fig. 1 illustrates a new demand curve with no increase in demand but a $600 \mathrm{ktCO}_{2}$-e decrease in the emissions levels. The supply composite curve is shifted to the right until the supply and demand curves intersect and the point at which they cross is known as the "Pinch Point". The amount that the supply has been shifted then becomes the amount of renewables (zero emissions) that need to be added in order for the target to be met. The overhang of the supply curve to the right of the pinch point represents the amount and type of generation that needs to be substituted with renewables. The amount of renewables needed to meet the target would need to be increased if fuel types below the pinch point were substituted instead of those above. Likewise if nonzero emission generation sources are substituted instead the generation profile would also be different for the target to be met. In this example the amount of generation from Fuel A could be increased in addition to adding renewables in order to reach the targets, however it is clear that this amount is constrained by the pinch point. 


\section{Incorporating Increased Demand}

The methodology outlined above can be extended to include an increase in demand in addition to a decrease in emissions. An increase in the electricity demand can be accounted for by shifting the demand composite curve so that the end of the line falls on the forecast demand and emissions target. The supply composite curve is once again shifted to the right until the demand and supply curves intersect. Essentially to account for both increased demand and reduced emissions the pinch point is shifted to the required target. The example from above has been extended to include an increase in demand of 200 GWh for the same emissions target and the new composite curves are shown in Fig. 2.

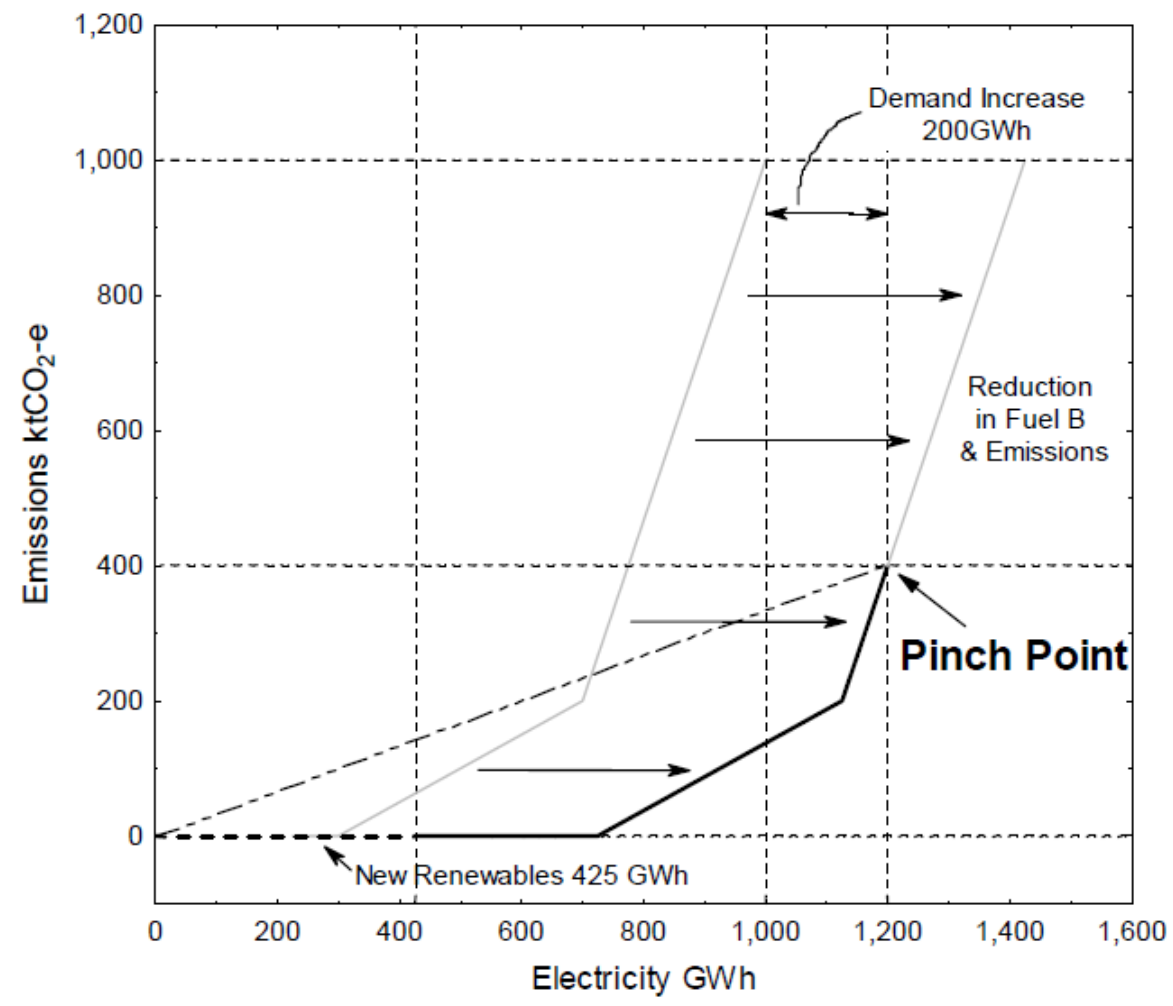

Fig. 2: Modified composite curves to include increased demand.

\section{New Zealand Electricity Sector}


The electricity sector in NZ has experienced consistent growth in the demand since 1990 and a corresponding increase in net emissions. Superimposed over the natural increase in demand and generation capacity has been far reaching and significant restructuring of the electricity industry, which has had a profound affect on investment behaviour of both generators and distributors [16]. The increase in demand from 1990 to 2007 averaged $1.77 \%$ per year (solid grey line) and there has been an increasing trend to higher GEF over the same period, which demonstrates that the increase in demand has been satisfied predominantly by fossil-fuel based generation as shown in Fig. 3. The GEF is sensitive to the generation mix and also the level of the hydro storage lakes, which is illustrated by the sharp jump in the GEF in 1992 due to a “dry year' and low hydro-lake levels. The dashed grey line is an adjusted forecast based on New Zealand Electricity Commission data [17] and projects that demand will increase on average $1.32 \%$ per year over the next two decades.

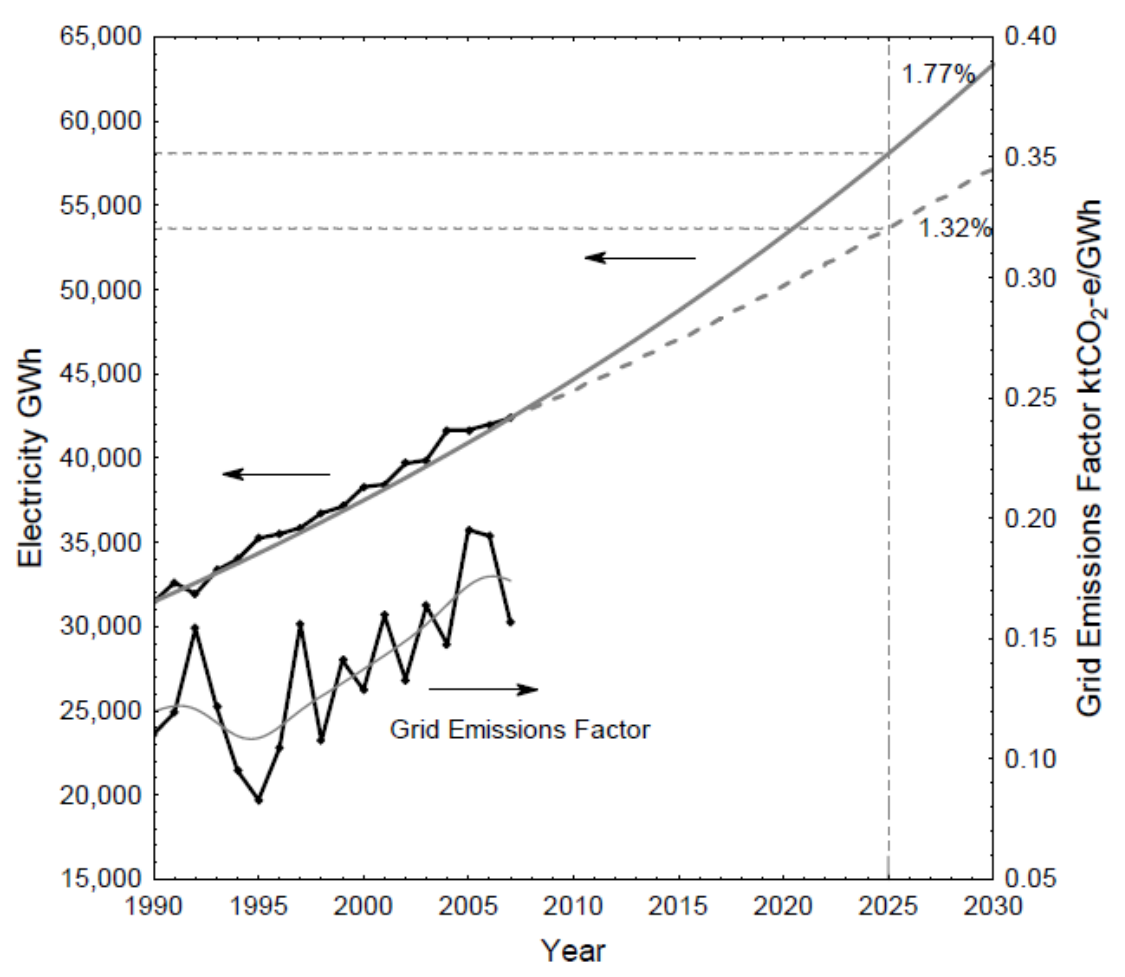

Fig. 3: Historical and forecast demand and Grid Emissions Factors. 
The total electricity demand and emissions for $\mathrm{NZ}$ in 2007 were $42,373 \mathrm{GWh}$ and $6,864 \mathrm{ktCO}_{2}$-e respectively $\left(\mathrm{GEF}=0.162 \mathrm{ktCO}_{2}-\mathrm{e} / \mathrm{GWh}\right)$ and the generation mix for that year is shown in Fig 4 . The total amount generated from renewables (including geothermal) was 67\%, with the remainder from fossilfuel based thermal generation. The demand composite curve has combined the demand from the various sectors so that only an aggregated demand curve is shown. Emissions factors were calculated based on data from the Ministry of Economic Development (MED) Energy Data Set [18].

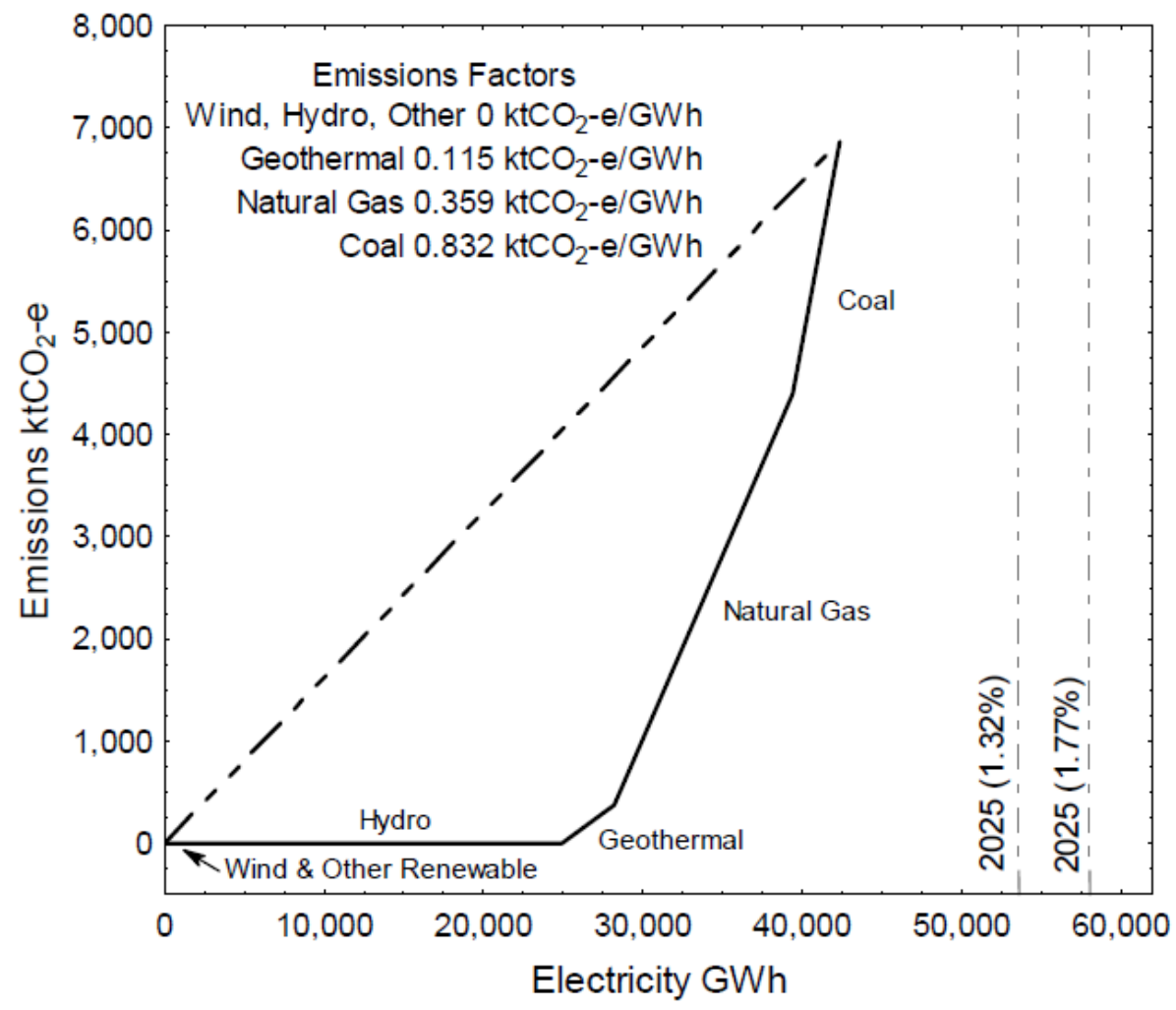

Fig. 4: Generation Mix for 2007.

It is important to note that although geothermal generation is often referred to as renewable generation it does have an emissions factor and for the current scenario the aggregate emissions factors for all geothermal generation is $0.115 \mathrm{ktCO}_{2}-\mathrm{e} / \mathrm{GWh}$. This emissions factor is highly site specific and can vary by almost two orders of magnitude depending on the geology and fluid circulation within the geothermal field. In this work the average emissions factor is used however future work will consider the individual geothermal fields and the effect on the emissions factor. In this case the emissions factors for the individual fields range from $0.043 \mathrm{ktCO}_{2}-\mathrm{e} / \mathrm{GWh}$ to $0.69 \mathrm{ktCO}_{2}-\mathrm{e} / \mathrm{GWh}$. However the average emissions 
factor will not be affect significantly because the one geothermal field that has a very high emissions factor $\left(0.69 \mathrm{ktCO}_{2}-\mathrm{e} / \mathrm{GWh}\right)$ is relatively small and has limited potential for further generation.

If a lifecycle approach is taken, all of the renewable generation sources have emissions factors due to construction, materials, maintenance, and the like. Lifecycle emission factors reported in the literature vary considerably depending of the technology and location [19]. For example, estimates for wind generation range from around $0.013 \mathrm{ktCO}_{2}$-e/GWh for heavy foundations in Japan (load factor of $25 \%$ ) to $0.0025 \mathrm{ktCO}_{2}-\mathrm{e} / \mathrm{GWh}$ for offshore wind in the UK (load factor of 30\%) [20]. Similar variation is found for other renewable technologies such as hydro, biomass, and for nuclear. Obviously there is great uncertainty in the estimates of life cycle emissions due to differences in the assessment methodology, conversion efficiency, and the like. Despite the variation, the life cycle estimates for wind and hydro are typically at least one to two orders of magnitude lower than geothermal and fossil-fuel based thermal generation and therefore the life cycle emissions have been ignored in this analysis.

The generation mix for the years 1990, 2006, and 2007 are illustrated in Fig. 5 along with two demand increase forecasts: the historic average since 1990 (1.77\%) and the Electricity Commission forecast (1.32\%) (see Fig. 3). The difference between the two forecasts in 2025 is around 4,500 GWh. The additional installed generation capacity needed between the two forecasts is around $640 \mathrm{MW}^{2}$, which represents a significant investment (over NZ\$1.5 billion) and more than adequately justifies considerable additional investment over current levels for efficiency measures and demand-side management.

The generation mix from 1990 to 2006 and 2007 has changed significantly with the bulk of the increased generation coming from geothermal (which has doubled since 1990) and the remainder from a large increase in natural gas and coal. Only a minor increase in generation from hydro or wind has occurred since 1990. It should also be pointed out that the emissions factors for coal and natural gas have improved slightly since 1990 as a result of efficiency increases due to the increased use of combine cycle gas turbines for example.

\footnotetext{
${ }^{2}$ This figure assumes a load factor of $80 \%$. This figure would more than double if this extra generation was supplied by wind or another renewable source with a relatively low load factor of $30 \%$.
} 


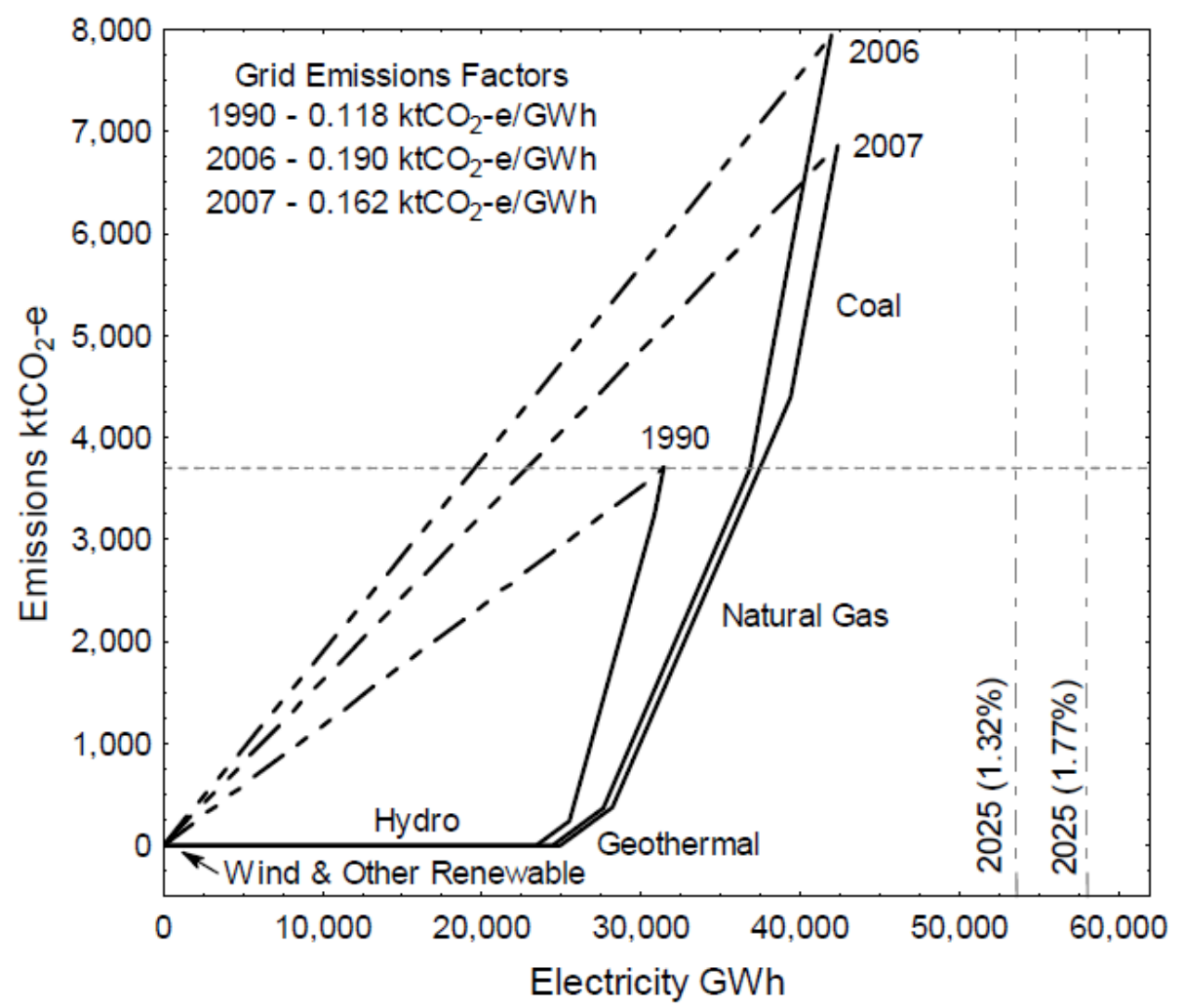

Fig. 5: Generation Profiles for 1990, 2006, \& 2007 and predicted demand in 2025.

Emissions from the electricity sector have almost doubled from 3,700 $\mathrm{ktCO}_{2}$-e in 1990 to just less than 7,000 $\mathrm{ktCO}_{2}$-e in 2007. Emissions peaked in 2005 and 2006 when emissions were around 8,000 $\mathrm{ktCO}_{2}$-e. There was a $14 \%$ reduction in emissions from 2006 to 2007 due to the replacement of coal with natural gas. There was also a $0.9 \%$ increase in demand from 2006 to 2007 . This trend of decreasing emissions is not expected to continue from 2007 to 2008 as there have been serious supply concerns during the first half of the year due to low hyro-lake levels. As a result the national back-up diesel generation facility at Whirinaki has been in use a considerable amount during the first half of 2008. Thus emissions for 2008 are expected to return and possibly exceed 2005/2006 levels due to the burning of millions of litres of diesel at the Whirinaki facility.

The Kyoto target is shown by the horizontal black dashed line and the dashed red arrow indicates the increase in demand (1.5\%) by 2012 and the Kyoto emissions target. The Kyoto liability from the electricity sector will be the total emissions above the 1990 level from 2008 to 2012 . To reduce the emissions to 1990 levels by 2012 would require a huge increase in investment to build new renewable 
generation capacity and bring it online quickly. When the time for planning, construction, and commissioning is considered, it is practically impossible to meet this target with new renewable sources. Instead the target for reducing emissions to 1990 levels is considered to be 2025 .

\section{Renewables Target $-\mathbf{9 0 \%}$}

A reduction in emission levels to 1990 levels while simultaneously meeting increased demand by 2025 has been set as the target in this study. The amount of new renewables (excluding geothermal) needed to satisfy the total demand while reducing emissions levels to 1990 levels by 2025 is illustrated in Fig. 6. To determine the minimum amount of new renewables needed the 2007 supply composite curve has been shifted to the right until the curve crosses the pinch point. It has been assumed that the demand growth rate will be $1.5 \%$ per year from 2007 until 2025 . This estimate of $1.5 \%$ is roughly half way between the historic growth rate $(1.77 \%)$ and the Electricity Commission forecast $(1.32 \%)$. At this growth rate the demand in 2025 is equal to 55,396 GWh, illustrated by the vertical dashed line in Fig. 6.

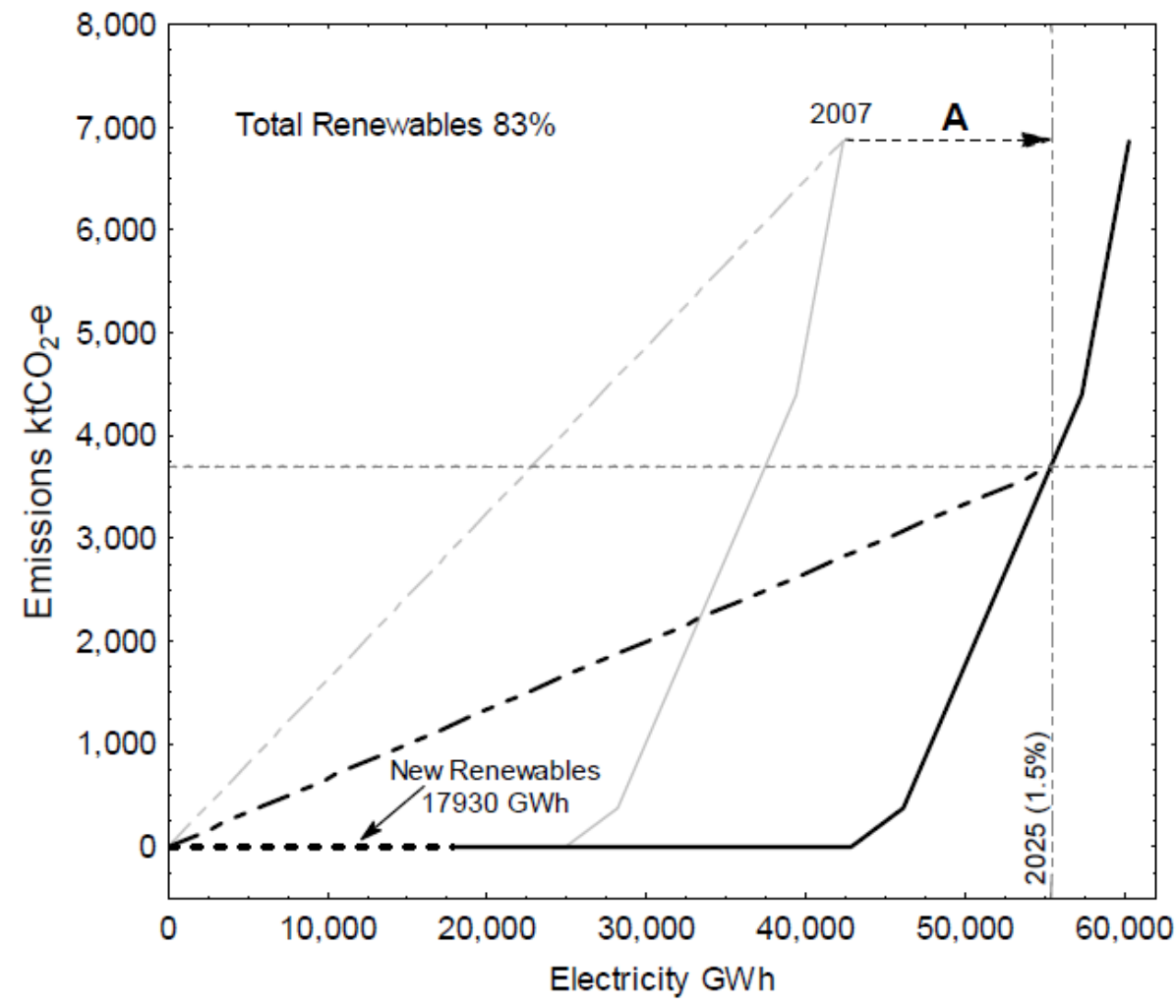

Fig. 6: Shifted Generation Profile for 2025 Kyoto Scenario. 
The total amount of new renewables (excluding geothermal) needed to meet the Kyoto target is 17,930 GWh. If extra geothermal is considered the increased emissions from this source of generation need to be included in the analysis. The amount of natural gas allowable would also be reduced if extra geothermal was added. The scenario presented in Fig. 6 increases the total proportion of renewables to $83 \%$ and therefore does not meet the renewables target. A likely generation mix to achieve the $90 \%$ renewables target (that includes the addition of geothermal) is considered later (Fig. 7).

It is obvious from Fig. 6 that if the current amount of generation from fossil-fuel thermal stations remains the same and renewables are added only to satisfy demand then there will be no reduction in total emissions. This scenario is shown by the horizontal dotted black arrow labelled $\mathrm{A}$ in the figure. The GEF or specific emissions will decrease slightly from 0.162 to $0.124 \mathrm{ktCO}_{2}$-e/GWh, however total emissions will stabilise and the Kyoto target will be substantially exceeded. If the Kyoto target is reached in 2025 the GEF will be equal to $0.064 \mathrm{ktCO}_{2}-\mathrm{e} / \mathrm{GWh}$, which is a $40 \%$ reduction in GEF from 2007 . A comparison of the GEF for several OECD countries and China is given in Table 2 as well as the proportion of renewables and nuclear. It is evident that very low GEF are obtainable where the amount of renewables is high (e.g. NZ) but also with moderate amounts of renewables combined with nuclear energy. While nuclear generation has been discounted at this stage for New Zealand, it is likely that the debate over nuclear energy will continue especially when the prime renewable energy resources have been utilised and the costs of renewable energy increases as non-conventional renewable resources such as marine and solar energy are exploited.

New Zealand has already utilised a large amount of renewable energy mainly in the form of hydro. It is unlikely that the additional renewables will come from wind and hydro alone and therefore increased geothermal also needs to be considered. Furthermore, there is also an upper limit to the amount of wind generation that the transmission system can adequately handle, and the accepted estimate of the feasible limit is around $20 \%$ [22]. It should be pointed out that as the amount of wind generation increases so does the amount of spinning reserve that is needed in order to ensure stable supply. Currently there is a slight surplus of spinning reserve, however as more wind is added, extra spinning reserve will need to be made available. 
Table 2 Grid Emissions Factors for several countries.

\begin{tabular}{|c|c|c|c|c|c|}
\hline Country & $\begin{array}{c}\text { Total } \\
\text { Emissions } \\
\text { (ktCO2-e) }\end{array}$ & $\begin{array}{c}\text { Total } \\
\text { Electricity } \\
\text { (GWh) }\end{array}$ & $\begin{array}{c}\text { Grid Emissions } \\
\text { Factor } \\
\left(\mathrm{ktCO}_{2}-\mathrm{e} / \mathrm{GWh}\right)\end{array}$ & $\begin{array}{c}\text { Renewables }^{\mathbf{b}} \\
\%\end{array}$ & $\begin{array}{c}\text { Nuclear } \\
\%\end{array}$ \\
\hline New Zealand & 6,864 & 42,373 & 0.162 & 67 & 0 \\
\hline New Zealand & 3,542 & 55,396 & 0.064 & 90 & 0 \\
\hline Australia $^{\mathrm{a}}$ & 189,000 & 190,000 & 0.99 & 8 & 0 \\
\hline $\mathrm{USA}^{\mathrm{a}}$ & $2,820,000$ & $4,190,000$ & 0.67 & 11 & 18 \\
\hline $\mathrm{UK}^{\mathrm{a}}$ & 227,000 & 370,000 & 0.61 & 7 & 20 \\
\hline Canada $^{a}$ & 172,000 & 732,000 & 0.23 & 54 & 12 \\
\hline France $^{a}$ & 53,300 & 551,000 & 0.10 & 12 & 78 \\
\hline Sweden $^{\mathrm{a}}$ & 2,860 & 154,000 & 0.02 & 51 & 45 \\
\hline China $^{a}$ & $3,120,000$ & $3,260,000$ & 0.96 & 15 & 2 \\
\hline
\end{tabular}

${ }^{\mathrm{a}}$ Data for 2007 from [21].

${ }^{\mathrm{b}}$ Includes hydro but excludes nuclear.

A possible generation mix that achieves the $90 \%$ renewables target in 2025 is shown in Fig. 7 . The additional renewables includes wind and hydro as well as geothermal. The amount of fossil-fuel based thermal generation is fixed at $10 \%$ of the total demand and it was assumed that this thermal generation would come from natural gas at the 2007 emissions factor. Likewise the emissions factor for the additional geothermal generation was also assumed to be at the 2007 value. The amount of new wind, hydro, and geothermal needed is shown Table 3. These figures roughly correspond to those estimated by the Energy Efficiency and Conservation Authority (EECA) in the advice to the Energy Minister concerning various renewables targets [23]. 
Table 3 Additional generation needed to reach the $90 \%$ renewable target.

\begin{tabular}{cccc}
\hline & Wind & Hydro & Geothermal \\
\hline Additional Generation (GWh) & 6648 & 4762 & 10238 \\
Additional Installed Capacity (MW) & 2530 & 1090 & 1460 \\
Load Factor & $30 \%$ & $50 \%$ & $80 \%$ \\
\hline
\end{tabular}

The increase in geothermal to reach the target represents a four fold increase over 2007 levels. It has been estimated that there is between 2,500 and 5,000 MW of high temperature geothermal generation potential existing in New Zealand based on current technology [24]. The average emissions factor for geothermal is not significantly altered when the specific emissions factor for the individual geothermal sites are included in the analysis. The authors have recently shown that if the individual fields are considered the average emissions factor from geothermal for a four-fold increase in generation capacity is within $18 \%$ of the emissions factor used here $\left(0.136 \mathrm{ktCO}_{2}-\mathrm{e} / \mathrm{GWh}\right)$ [25]. The actual value is highly dependant on which fields are developed and by how much. The average emissions factor for 2007 is used here because it is a good first order approximation. The overall shape of the supply composite curve is not significantly altered if the higher emissions factor for geothermal is used although there is a $6 \%$ increase in total emissions for the higher emissions factor. Meeting the required additional installed capacity for geothermal is obtainable based on these estimates although reaching this target is by no means certain.

To reach the $90 \%$ renewables target presented in Fig. 7 would require the elimination of significant amounts of current installed thermal generation capacity. The reduction in generation from natural gas would need to be reduced by around $50 \%$ from 11,200 to $5,540 \mathrm{GWh}$, which amounts to only two Combine Cycle Gas Turbines (CCGT) of around $350 \mathrm{MW}$ each. CCS has been excluded at this stage as there has been little interest shown by both generators and regulators into seriously examining the potential for CCS in the New Zealand context. The potential implications on security of supply (especially in dry years), increase in the cost of electricity across all sectors, and transmission issues of a 
$90 \%$ renewables scenario all need to be more thoroughly analysed and debated in the public and political arena.

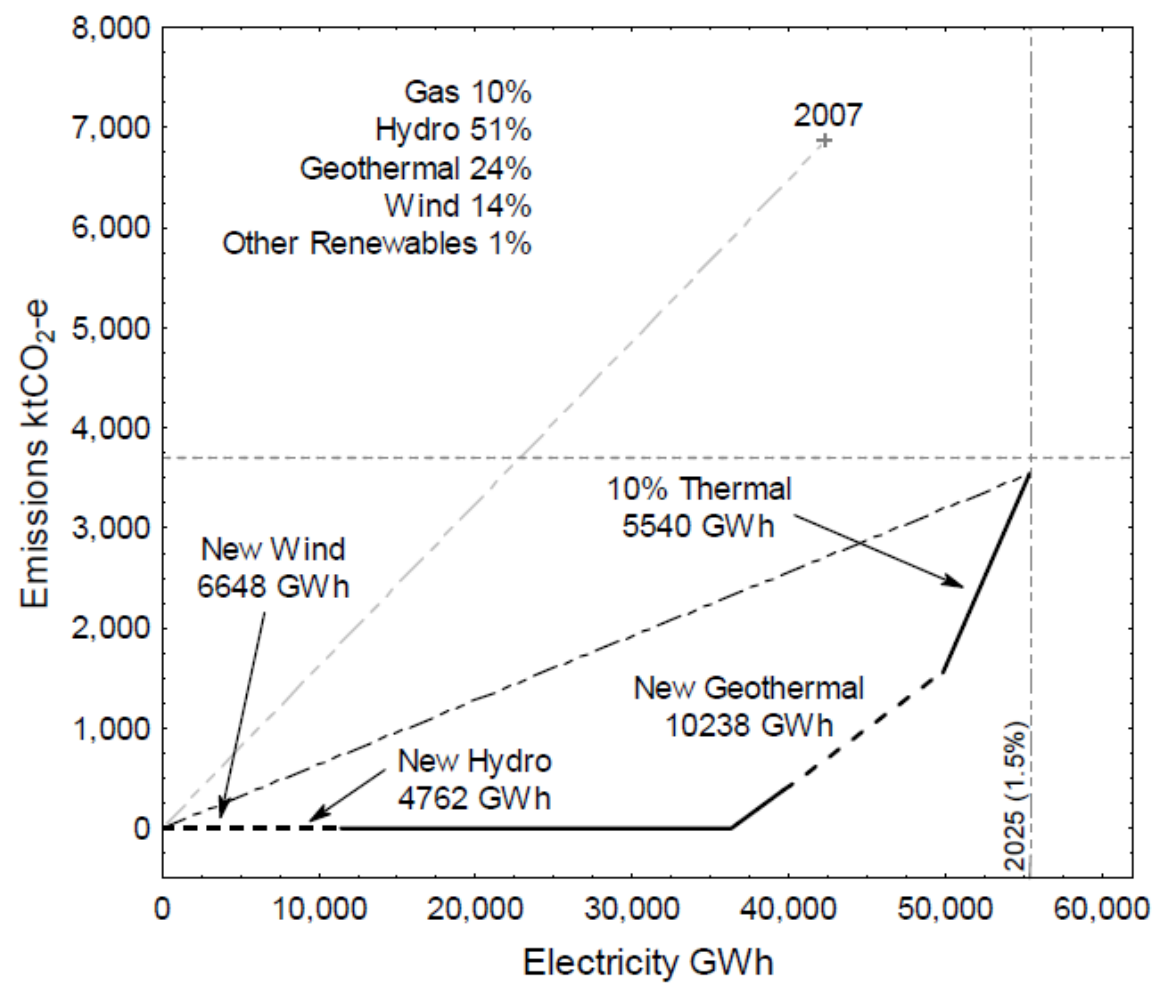

Fig. 7: 90\% Renewables Target 2025.

\section{Conclusions}

Carbon Emissions Pinch Analysis is a useful technique for macro-level regional or sectoral emissions planning and targeting and has been applied to the New Zealand electricity sector. There have been substantial increases in carbon emissions from 1990 to 2007, and large decreases in current emissions will need significant increases in renewable generation and an extensive reduction in the fossil-fuel based thermal generation. A $90 \%$ renewable energy target for the electricity sector could be met by 2025 with careful planning, although the economic merits of a renewables target needs to be more fully explored. 


\section{References}

[1] Ministry of Economic Development. New Zealand Energy Strategy, $<$ http://www.med.govt.nz/templates/ContentTopicSummary 19431.aspx>. [accessed 20 Oct 2008].

[2] Bardsley WE. Note on the pumped storage potential of the Onslow-Manrburn depression, New Zealand. Journal of Hydrology (NZ) 2005;44:131-5.

[3] Tan RR, Foo DCY. Pinch analysis approach to carbon-constrained energy sector planning. Energy 2007;32(8):1422-9.

[4] Lee SC, Ng DKS, Foo DCY, Tan RR. Extended pinch targeting techniques for carbonconstrained energy sector planning. Applied Energy 2009;86(1):60-7.

[5] Foo DCY, Tan RR, Ng DKS. Carbon and footprint-constrained energy planning using cascade analysis technique. Energy 2008;33(10):1480-8.

[6] Kemp IC. Pinch analysis and process integration: A users guide on process integration for the efficient use of energy. Oxford, UK: Butterworth-Heinemann; 2007.

[7] Smith R. Chemical process design and integration. Chichester, UK: John Wiley \& Sons Ltd; 2005.

[8] El-Halwagi MM. Process integration, process systems engineering Vol. 7. San Diego: Elsevier; 2006.

[9] Mann JG, Liu YA. Industrial water reuse and wastewater minimization. New York: McGrawHill; 1999.

[10] Linnhoff $\mathrm{B}$, Dhole VR. Targeting for $\mathrm{CO}_{2}$ emissions for total sites. Chemical Engineering Technology 1993;16:252-9.

[11] Crilly D, Zhelev T. Emissions targeting and planning: An application of $\mathrm{CO}_{2}$ emissions pinch analysis (CEPA) to the Irish electricity generation sector. Energy 2008;33(10):1498-1507. 
[12] Crilly D, Zhelev T. Further emissions and energy targeting: an application of $\mathrm{CO}_{2}$ emissions pinch analysis to the Irish electricity sector. Clean Technologies and Environmental Policy; doi:10.1007/s10098-009-0245-0.

[13] Crilly D, Zhelev T. Expanded emissions and energy targeting: a further application of $\mathrm{CO}_{2}$ emissions pinch analysis (CEPA) to the Irish electricity generation sector. Chemical Engineering Transactions 18:75-80.

[14] Tan RR, Ng DKS, Foo DCY. Pinch analysis approach to carbon-constrained planning for sustainable power generation. Journal of Cleaner Production; doi:10.1016/j.jclepro.2009.02.007.

[15] Tan RR, Foo DC. Recent trends in pinch analysis for carbon emissions and energy footprint problems. Chemical Engineering Transactions 18:249-254.

[16] Barton B. Reaching the limits of what the market will provide: Energy security in New Zealand. In Energy security: Managing risk in a dynamic legal and regulatory environment. Barton B, Redgwell C, Rønne A, Zillman D, (eds). Oxford, UK: Oxford University Press; 2004.

[17] New Zealand Electricity Commission. $<$ www.electricitycommission.govt.nz/pdfs/opdev/modelling/demand-forecast08/NationalRegionalEnergy ForecastsMar08.xls>. [accessed 20 Oct 2008].

[18] Ministry of Economic Development. $<$ http://www.med.govt.nz/templates/ContentTopicSummary__ 20511.aspx $>$. [accessed 20 Oct 2008].

[19] Weisser D. A guide to life-cycle greenhouse gas (GHG) emissions from electric supply technologies. Energy 2007;32:1543-1559.

[20] Spadaro JV, Langlois L, Hamilton B. Greenhouse gas emissions of electricity generation chains: Assessing the difference. IAEA Bulletin; 42/2/2000.

[21] CARMA. <www.carma.org>. [accessed 21 Nov 2008].

[22] Energy Link \& MWH New Zealand Ltd. Wind energy integration in New Zealand; 2005. 
[23] EECA. The implications of higher proportions of renewable electricity by 2030; 2007.

[24] Lawless JV. New Zealand's geothermal resource revisited. New Zealand Geothermal Association Annual Seminar, Taupo; 2002.

[25] Atkins MJ, Walmsley MWR, Morrison A. Kamp PJJ. Carbon emissions pinch analysis (CEPA) for emissions reduction in the New Zealand electricity sector. Chemical Engineering Transactions $18: 261-266$ 